Ekspose Volume 16, Nomor 1, Januari - Juni 2017

P-ISSN: 1412-2715, E-ISSN: 2616-4412

\title{
METODE PEMAHAMAN HADIS
}

\author{
Muhammad Asriady \\ Institut Parahikma Indonesia (IPI), Indonesia \\ e-mail: muhammadasriady@gmail.com
}

\begin{abstract}
The understanding of hadith method is the way to understand the hadith. The book entitled Methodology of Understanding Hadiths written by Arifuddin Ahmad was developed into several techniques, such as textual interpretation techniques, contextual interpretations and intertextual interpretations. In this study, writer used library research methodology. The development of hadith from time to time is very fast, so in understanding the hadith there were various methods. Researchers, and observers must be understand the methodology, so that the diverse views on Islam can be understood in depth, it can bringing the people to the Rahmatan lil Alamin.
\end{abstract}

Keywords: Methode, Hadith.

\section{Pendahuluan}

Kajian Hadis memiliki posisi yang sangat penting, karena Hadis merupakan sumber kedua setelah Al Qur'an. Kajian Hadis terbagi beberapa pembahasan, diantaranya: kajian ilmu mustalah al Hadis, kritik sanad dan matan, serta berkaitan dengan pemahaman Hadis. Banyak ulama klasik dan ulama kontemporer yang menulis buku Hadis sehingga sangat mudah mendapatkan akses untuk melakukan pengkajian hadis. ${ }^{1}$ Hadis atau Sunnah adalah segala sesuatu yang dinisbatkan kepada Nabi Muhammad saw. baik berupa perkataan, perbuatan, ketetapan maupun sifatnya baik sebelum diangkat menjadi Rasul atau sesudahnya. ${ }^{2}$

Secara epistomologi, hadis dipandang oleh mayoritas umat Islam sebagai sumber ajaran Islam setelah al Qur'an. Sebab, ia merupakan bayan (penjelasan) terhadap ayat ayat al Qur'an yang masih global. Bahkan secara mandiri, hadis dapat berfungsi menetapkan suatu hukum yang belum ditetapkan oleh al Qur'an. ${ }^{3}$ Selain itu, al Sunnah oleh Yusuf Qardhawi, adalah penafsiran praktis terhadap al Qur'an, implementasi realitas, dan juga implementasi ideal Islam. Pribadi nabi Muhammad SAW. itu sendiri adalah merupakan penafsiran al Qur'an dan pengejawantahan Islam. ${ }^{4}$ Keberadaan hadis tidak hanya telah mewarnai masyarakat dalam berbagai kehidupan, terutama dalam

\footnotetext{
${ }^{1}$ Ali Mustafa Yaqub, Cara Benar Memahami Hadis (Pejaten Barat Jakarta: Pustaka Firdaus, 2016), h. xi.

${ }^{2}$ Subhi al-Salih, 'Ulum al-Hadis wa Mustalah (Beirut: Dar al-Ilm al-Malayin, 1977), h. 3.

${ }^{3}$ Wahbah al-Zuhaili, Al-Qur'an al-Karim wa Bunyatuhu al-Tasyri'iyyah wa khasa'isuhu alKhadariyyah (Beirut: Dar al-Fikr, 1993), h. 48.

${ }^{4}$ Yusuf Qardawi, Kaifa Nata'amal ma'a al-Sunnah al-Nabawiyyah: Ma'alim wa Dawabit, terj. Saifullah Kamalie, Metode Memahami as-Sunnah dengan Benar (Jakarta: Media Da'wah, 1994), h. 28.
} 
dunia akademisi. Akan tetapi, juga telah menjadi bahasan dalam kajian dan penelitian yang menarik dan tiada hentinya, termasuk metode pemahaman hadis beserta aplikasinya. Untuk itu, penulis akan membahas mengenai metode pemahaman hadis.

\section{Pengertian Metode Pemahaman Hadis}

Segala sesuatu butuh cara untuk mengetahui maksud tertentu, begitupula dengan hadis Nabi, butuh metode pemahaman agar hadis itu mampu diketahui, dimengerti, dipahami, kemudian diamalkan. Di dalam kamus bahasa Indonesia, metode adalah cara yang teratur berdasarkan pemikiran yang matang untuk mencapai maksud (dalam ilmu pengetahuan tersebut); cara kerja yang teratur dan bersistem untuk dapat melaksanakan suatu kegiatan dengan mudah guna mencapai maksud yang ditentukan. ${ }^{5}$ Metodologi juga berasal dari kata 'method' yang berarti cara atau tekhnik, metode juga diartikan sebagai cara teratur yang digunakan untuk melaksanakan pekerjaan agar tercapai tujuan sesuai yang dikehendaki. ${ }^{6}$

Pemahaman berasal dari kata paham yang berarti pengertian, pendapat atau pikiran, aliran atau haluan pandangan, mengerti benar atau tahu benar, pandai dan mengerti benar (tentang suatu hal). Sementara pemahaman adalah proses, cara perbuatan memahami atau memahamkan. Jadi, metode pemahaman hadis adalah cara yang ditempuh sesorang untuk memahami hadis. Metodologi pemahaman hadis dalam buku yang ditulis oleh Arifuddin Ahmad bahwa metodologi pemahaman diartikan tekhnik interpretasi, dimana dibagi menjadi interpretasi tekstual, interpretasi konteksual dan interpretasi intertesktual.

\section{Prinsip prinsip Metodologi Memahami Hadis}

Memahami hadis tidak semudah dengan membalikkan telapak tangan, sehingga ulama melakukan kajian secara serius mengenai bagaimana cara untuk memahami hadis. Dari itu para ulama memberikan beberapa prinsip umum sebagaimana tulisan dari Abdul Mustaqim ${ }^{7}$ dalam memahami hadis Nabi saw.:

1. Prinsip jangan terburu buru menolak hadis yang dianggap bertentangan dengan akal, sebelum melakukan penelitian yang mendalam.

2. Prinsip memahami hadis secara tematik (maudhu'i) sehingga memperoleh gambaran utuh mengenai tema yang dikaji Ali Mustafa Yaqub menyatakan hadis

\footnotetext{
${ }^{5}$ Departemen Pendidikan Nasional, Kamus Bahasa Indonesia (Jakarta: Pusat Bahasa, 2008), h. 952.

${ }^{6}$ Arifuddin Ahmad, Metodologi Pemahaman Hadis; Kajian Ilmu Ma'ani al-Hadis (Makassar: Alauddin University Press, 2012), h. 3.

${ }^{7}$ Dosen Ilmu Al-Qur'an dan Tafsir Fakultas Ushuluddin dan Pemikiran UIN Sunan Kalijaga Yogyakarta, dan Pengasuh Pondok Pesantren Mahasiswa LSQ (Lingkar Studi al-Qur'an) al-Rohman Bantul Yogyakarta.
} 
saling menafsirkan karena sumbernya adalah Raasulullah dan untuk memahaminya harus dengan melihat riwayat yang lain.

3. Prinsip bertumpu pada analisis kebahasaan, mempertimbangkan struktur teks dan konteks.

4. Prinsip membedakan Antara ketentuan hadis yang bersifat legal formal dengan aspek yang bersifat ideal moral (baca: sesatu yang hendak dituju), membedakan sarana dan tujuan.

5. Prinsip bagaimana membedakan hadis yang bersifat lokal kultural, temporal dan universal.

6. Mempertimbangkan kedudukan Nabi saw. apakah beliau sebagai manusia biasa, nabi atau rasul, hakim, panglima perang, ayah dan lain sebagainya. Sehingga pengkaji dan peneliti hadis harus cermat menangkap makna yang terkandung dibalik teks tersebut.

7. Meneliti dengan seksama tentang kesahihan hadis, baik sanad dan matan, serta berusaha memahami segala aspek yang terkait dengan metode pemahaman hadis.

8. Memastikan bahwa teks hadis tersebut tidak bertentangan dengan nash yang lebih kuat.

9. Menginterkoneksikan dengan teori teori sains modern untuk memperoleh kejelasan makna tentang isyarat isyarat ilmiah yang terkadung dalam hadis hadis sains. $^{8}$

Beberapa poin mengenai prinsip prinsip memahami hadis Nabi tersebut bukanlah merupakan hal yang final, boleh dikembangkan pada hal yang lebih luas sesuai dengan kebutuhan memahami hadis Nabi.

\section{Teknik Interpretasi}

Tekhnik interpretasi dapat diartikan sebagai metode atau cara menafsirkan sesuatu, dimana pada tulisan ini adalah tekhnik interpretasi terhadap Hadis.

\section{Interpretasi Tekstual}

Interpretasi tekstual adalah pemahaman terhadap matan hadis berdasarkan teksnya semata. Teknik interpretasi ini cenderung mengabaikan latar belakang peristiwa hadis (asbab al wurud). ${ }^{9}$ Dasar penggunaan teknik ini adalah setiap ucapan dan perilaku Nabi saw. tidak terlepas dari konteks kewahyuan bahwa segala sesuatu yang disandarkan kepada Rasulullah adalah wahyu. Sebagaimana dalam QS al Najm/53: 34 yang berbunyi,

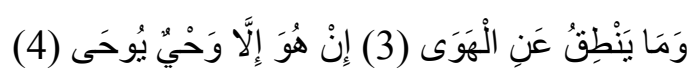

\footnotetext{
${ }^{8}$ Abdul Mustaqim, Ilmu Ma'anil Hadis: Paradigma Interkoneksi berbagai teori dan metode memahami hadis nabi (Cet. II: Bantul Yogyakarta; Idea Press Yogyakarta, 2016), h. 33-36.

${ }^{9}$ Arifuddin Ahmad, Metodologi Pemahaman Hadis; Kajian Ilmu Ma'ani al-Hadis, h. 19.
} 
Artinya: dan tiadalah yang diucapkan itu (al Qur'an) menurut kemauan hawa nafsunya. Ucapannya itu tiada lain hanyalah wahyu yang diwahyukan (kepadanya). ${ }^{10}$

Karena itu, apa yang dinyatakan secara eksplisit sebagai hadis Nabi seharusnya dipahami seperti apa adanya kecuali dijumpai kesulitan, maka harus ditakwilkan. Hal yang perlu diperhatikan dalam teknik interpretasi ini adalah bentuk bentuk lafal, susunan kalimat, frase dan klausa, gaya bahasa, kejelasan lafal, petunjuk (dalalah), makna kandungan lafal baik bersifat hakiki maupun majazi. ${ }^{11}$ Pendekatan yang digunakan untuk teknik interpretasi ini adalah pendekatan linguistik, teologi normatif dan teologis (kaidah kaidah ushul fiqh). ${ }^{12}$ Contoh pengaplikasian interpretasi ini adalah bentuk matan hadis yang berupa jawami' al kalim, yakni sebagai berikut.

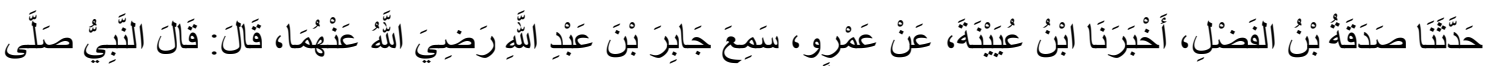

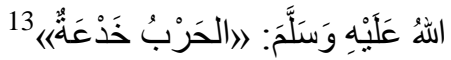

Artinya: Telah bercerita kepada kami Sadaqah bin al Fadl, telah mengabarkan kepada kami Ibn 'Uyainah dari 'Amr dia mendengar Jabir bin 'Abdullah ra. berkata; Nabi saw. bersabda: "Perang adalah siasat".

Pemahaman terhadap petunjuk hadis tersebut sejalan dengan bunyi teksnya yakni setiap perang pastilah memakai siasat. Ketentuan yang demikian itu, berlaku universal sebab tidak terikat oleh tempat dan waktu tertentu. Perang yang dilakukan dengan cara dan alat apa saja pastilah memerlukan siasat. Perang tanpa siasat sama dengan menyatakan takluk kepada lawan tanpa syarat. ${ }^{14}$

\section{Interpretasi Kontekstual}

Interpretasi kontekstual adalah pemahaman terhadap matan hadis dengan memperhatikan asbab al wurud yang dihubungkan dengan konteks kekinian. ${ }^{15}$ Dasar penggunaan tehnik ini adalah Nabi Muhammad saw. adalah teladan terbaik, uswatun hasanah, sebagaimana dinyatakan dalam QS al Ahzab/33: 21 yang berbunyi,

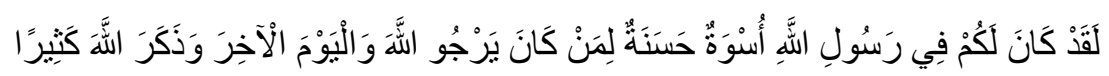

\footnotetext{
${ }^{10}$ Kementrian Agama RI., Mushaf al-Qur'an dan Terjemah (Bandung: Insan Kamil, 2009), h. 526.

${ }^{11}$ Ambo Asse, Studi Hadis Maudhu'i (Suatu Kajian Metodologi Holistik) (Cet. I; Makassar: Alauddin University Press, 2013), h. 138.

${ }^{12}$ Arifuddin Ahmad, Metodologi Pemahaman Hadis; Kajian Ilmu Ma'ani al-Hadis, h. 20.

${ }^{13}$ Muhammad bin Isma'il Abu 'Abdillah al-Bukhari, al-Jami' al-Sahih, Juz 4 (Cet. I; t.tt: Dar Tuq al-Najjah, 1422 H), h. 64. Selanjutnya disebut al-Bukhari

${ }^{14}$ M. Syuhudi Ismail, Hadis Nabi yang Tekstual dan Kontekstual; Telaah Ma'ani al-Hadits tentang Ajaran Islam yang Universal, Temporal dan Lokal (Cet. I; Jakarta: Bulan Bintang, 1994), h. 11.

${ }^{15}$ Arifuddin Ahmad, Metodologi Pemahaman Hadis; Kajian Ilmu Ma'ani al-Hadis, h. 113.
} 
Artinya: Sungguh telah ada pada diri Rasulullah itu suri teladan yang baik bagimu (yaitu) bagi orang yang mengharap (rahmat) Allah dan (kedatangan) hari kiamat dan yang banyak mengingat Allah. ${ }^{16}$

Rasulullah saw. diutus oleh Allah swt dengan membawa misi kerahmatan bagi seluruh alam, sebagaimana dinyatakan dalam QS al Anbiya'/21: 107 yang berbunyi,

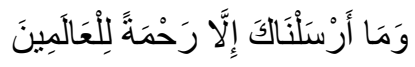

Artinya: Dan Kami tidak mengutus engkau (Muhammad) melainkan untuk (menjadi) rahmat bagi seluruh alam. ${ }^{17}$

Kedua ayat di atas, masing masing menegaskan bahwa segala sesuatu yang telah diperankan oleh Rasulullah saw. adalah patut untuk diteladani dan merupakan bagian dari perwujudan misi kerahmatannya. Oleh karena itu, semua pemahaman terhadap hadis hadis beliau yang menyalahi kedudukannya sebagai uswah hasanah atau misi kerahmatannya perlu ditinjau kembali. Dalam konteks inilah, maka pemahaman terhadap hadis Nabi memerlukan pertimbangan konteksnya, baik di saat hadis tersebut diwurudkan maupun tatkala hadis hadis itu akan diamalkan. Ini berarti bahwa hadis Nabi merupakan bukti kepatutan beliau menjadi teladan terbaik dan bukti kerahmatan misi yang dibawa oleh beliau, sekalipun beberapa di antaranya dianggap bertentangan dengan kemajuan zaman. ${ }^{18}$

Hal yang perlu diperhatikan dalam teknik interpretasi ini adalah peristiwa peristiwa yang terkait dengan wurud hadis (asbab al wurud), kondisi yang dialami dan dihadapi oleh Rasulullah saw pada saat beliau mengucapkan hadis itu atau pada saat beliau melakukan suatu amalan yang disaksikan oleh para sahabat atau memang bersama sama dengan para sahabatnya. ${ }^{19}$ Pendekatan yang dapat digunakan dalam teknik interpretasi ini adalah pendekatan historis, sosiologis, filosofis yang bersifat interdisipliner. ${ }^{20}$ Contoh pengaplikasian interpretasi ini adalah sebagai berikut.

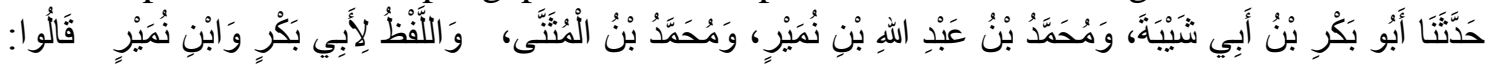

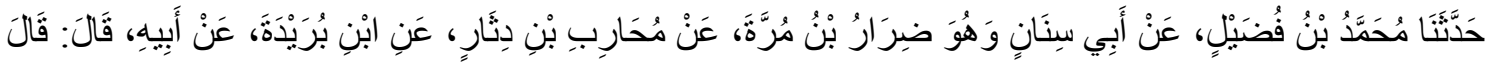

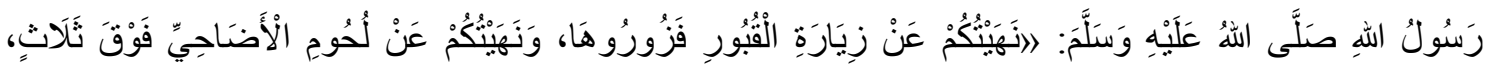

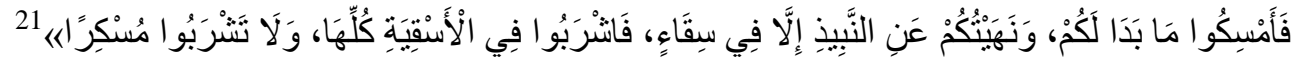

\footnotetext{
${ }^{16}$ Kementrian Agama RI., Mushaf al-Qur'an dan Terjemah, h. 420.

${ }^{17}$ Kementrian Agama RI., Mushaf al-Qur'an dan Terjemah, h. 331.

${ }^{18}$ Arifuddin Ahmad, Metodologi Pemahaman Hadis; Kajian Ilmu Ma'ani al-Hadis, h. 114.

${ }^{19}$ Ambo Asse, Studi Hadis Maudhu'i (Suatu Kajian Metodologi Holistik), h. 138.

${ }^{20}$ Ambo Asse, Studi Hadis Maudhu'i (Suatu Kajian Metodologi Holistik), h. 138.

${ }^{21}$ Muslim bin al-Hajjaj Abu al-Hasan al-Qusyiri al-Naisaburi, Sahih Muslim, Juz 2 (Beirut: Dar Ihya' al-Turas al-'Arabi, t.th.), h. 672.
} 
Artinya:

Telah menceritakan kepada kami Abu Bakar bin Abu Syaibah dan Muhammad bin 'Abdullah bin Numair dan Muhammad bin al Musanna - sedangkan lafaznya milik Abu Bakar dan Ibn Numair - mereka berkata, telah menceritakan kepada kami Muhammad bin Fudail dari Abu Sinan — Ia adalah Dirar bin Murrah—dari Muharib bin Disar dari Ibn Buraidah dari bapaknya ia berkata: Rasulullah saw. bersabda: "Dulu aku melarang kalian untuk ziarah kubur, maka sekarang berziarahlah. Dulu aku melarang kalian untuk menyimpan daging hewan kurban lebih dari tiga hari, maka sekarang simpanlah selama jelas bagimu manfaatnya. Dulu aku melarang kalian tentang nabiz selain di tempat minum, maka sekarang minumlah dengan menggunakan segala jenis tempat minum dan jangan meminum minuman yang memabukkan."

Berdasarkan redaksi hadis yang digunakan oleh Rasulullah saw. dalam hadis di atas dapat dipahami bahwa sebelum menyatakan sabdanya tersebut, beliau pernah melarang perbuatan tersebut. ${ }^{22}$

Ziarah kubur pada awal Islam dilarang karena pemeluk Islam masih lemah, masih berbaur dengan amalan jahiliyah yang dikhawatirkan dapat menyebabkan perbuatan syirik. Namun, setelah Islam kuat dan umat Islam sudah dapat membedakan mana perbuatan yang mengarah kepada syirik mana yang mengarah untuk beribadah kepada Allah, maka justru ziarah kubur diperintahkan karena dapat mengingatkan pelakunya tentang hari kematian dan hari akhirat. ${ }^{23}$

Jika mencermati konteks yang melatarbelakangi wurudnya hadis di atas, maka dapat dinyatakan bahwa perintah dan larangan ziarah kubur tetap berlaku bila dikhawatirkan pelakunya dapat berbuat kemusyrikan jika melakukan ziarah kubur. ${ }^{24}$

\section{Interpretasi Intertekstual}

Interpretasi intertekstual adalah pemahaman terhadap matan hadis dengan memperhatikan sistematika matan hadis bersangkutan atau hadis lain yang semakna atau ayat ayat al Qur'an yang terkait. ${ }^{25}$ Ambo Asse menamai teknik interpretasi ini dengan interpretasi antarteks. ${ }^{26}$ Teknik interpretasi ini disebut juga teknik munasabah.

Dasar penggunaan teknik ini adalah penegasan bahwa hadis Nabi adalah perilaku terhadap Nabi yang merupakan satu kesatuan dengan hadis lain atau ayat ayat al Qur'an. Bukankah hadis Nabi berfungsi sebagai bayan terhadap ayat ayat al Qur'an. ${ }^{27}$ Allah swt berfirman dalam QS al Nahl/16: 44 yang berbunyi,

\footnotetext{
${ }^{22}$ Arifuddin Ahmad, Metodologi Pemahaman Hadis; Kajian Ilmu Ma'ani al-Hadis, h. 160.

${ }^{23}$ Ibid, h. 161.

${ }^{24}$ Ibid, h. 161.

${ }^{25}$ Ibid, h. 85.

${ }^{26}$ Ambo Asse, Studi Hadis Maudhu'i (Suatu Kajian Metodologi Holistik), h. 138.

${ }^{27}$ Arifuddin Ahmad, op.cit, h. 85.
} 


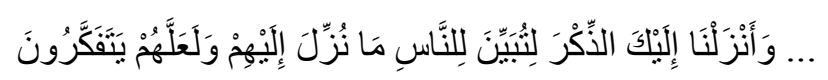

Artinya:...Dan Kami turunkan kepadamu al Qur'an agar kamu menerangkan kepada manusia apa yang telah diturunkan kepada mereka dan supaya mereka memikirkan. ${ }^{28}$

Ayat ini menjelaskan bahwa Rasulullah saw. diberi tugas sebagai orang yang memiliki kewenangan untuk menjelaskan ayat ayat al Qur'an. penjelasan Beliau itulah yang kemudian disebut sebagai hadis Nabi. Dengan demikian, pemahaman terhadap hadis seharusnya tidak memisahkan atau mengabaikan petunjuk al Qur'an yang terkait dengannya. ${ }^{29}$

Di samping itu, Nabi sebagai utusan Allah menyampaikan hadis secara bertahap sehingga memungkinkan suatu hadis dengan hadis yang lain dalam satu tema, berbeda dan tampak bertentangan. Dengan memahami hadis dengan interteks atau antarteks, diharapkan syarahan hadis dapat mengungkapkan kandungan yang lebih komprehensip dan sesuai dengan misi kerasulan beliau. ${ }^{30}$

Hal yang perlu diperhatikan dalam teknik interpretasi ini adalah hubungan antara teks teks hadis yang lain, baik yang berada dalam satu makna atau tema yang sama dengan melihat keragaman lafalnya. Dan yang perlu diperhatikan adalah hubungan antara teks teks hadis yang dikaji dengan ayat ayat al Qur'an sebagai sumber ajaran dan sumber hukum Islam, terutama yang berkaitan dengan hubungan fungsional antara hadis dengan al Qur'an. ${ }^{31}$

Contoh pengaplikasian interpretasi interteks atau antarteks ini adalah bayan taqrir di mana hadis berfungsi memperkuat apa yang telah diterangkan di dalam al Qur'an.

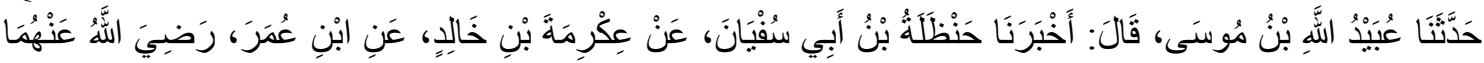

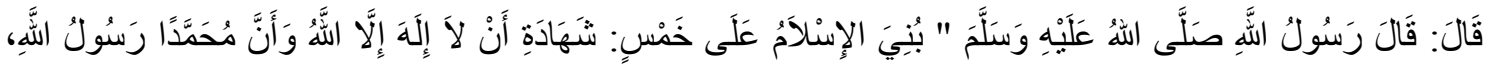

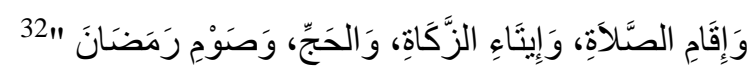

Artinya: Telah menceritakan kepada kami 'Abdullah bin Musa, dia berkata telah mengabarkan kepada kami Hanzalah bin Abu Sufyan dari 'Ikrimah bin Khalid dari Ibn 'Umar berkata: Rasulullah saw. bersabda: "Islam dibangun atas lima pondasi, yaitu persaksian tidak ada Tuhan selain Allah dan sesungguhnya Muhammad utusan Allah, mendirikan shalat, menunaikan zakat, haji dan puasa Ramadan”.

Hadis di atas memperkuat ayat ayat berikut.

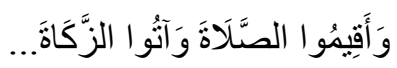

\footnotetext{
${ }^{28}$ Kementrian Agama RI., Mushaf al-Qur'an dan Terjemah, h. 272.

${ }^{29}$ Arifuddin Ahmad, op.cit, h. 85

${ }^{30}$ Ibid, h. 86.

${ }^{31}$ Ambo Asse, Studi Hadis Maudhu'i (Suatu Kajian Metodologi Holistik), h. 138.

${ }^{32}$ Al-Bukhari, al-Jami' al-Sahih, Juz 1, h. 11.
} 
Artinya: Laksanakanlah salat dan tunaikanlah zakat... ${ }^{33}$ (QS al Baqarah/2: 43)

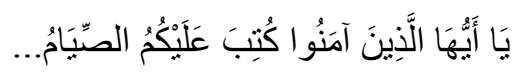

Artinya: Wahai orang orang yang beriman, diwajibkan atas kamu berpuasa... ${ }^{34}$ (QS al Baqarah/2: 183)

Contoh lainnya adalah munasabah hadis dalam satu matan sebagaimana hadis berikut ini.

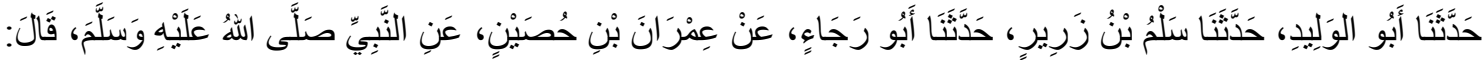

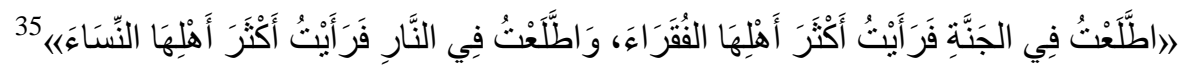

Artinya: Abu al Walid telah menceritakan kepada kami, Salm bin Zarir telah menceritakan kepada kami, Abu Raja' telah menceritakan kepada kami, dari 'Imran bin Husain dari Rasulullah saw. telah bersabda, "Saya melihat di surga, maka saya melihat penghuninya pada umumnya al fuqara'. Dan saya melihat di neraka, maka saya melihat penghuninya pada umumnya al nisa'.

Secara teks, hadis di atas menunjukkan bahwa umumnya penghuni surga dari kalangan al fuqara' dan umumnya penghuni neraka adalah al nisa'. Jika term al fuqara' diartikan orang orang fakir atau miskin, artinya orang miskin yang umumnya calon penghuni surga, maka seharusnya yang umumnya masuk neraka adalah al gani' atau orang kaya. Sebaliknya, jika term al nisa' diartikan sebagai jenis kelamin perempuan artinya kaum perempuan yang umumnya calon penghuni neraka, maka seharusnya yang umumnya masuk surga adalah al rijal atau kaum lelaki. ${ }^{36}$ Ternyata, redaksi hadis di atas tidak menyebutkan term al fuqara' sebagai lawan dari al gani atau term al nisa' sebagai lawan al rijal. Oleh karena itu, redaksi hadis di atas tidak seharusnya dipahami bahwa umumnya calon penghuni surga adalah mereka yang fakir dan umumnya calon penghuni neraka adalah mereka yang berjenis kelamin perempuan. Akan tetapi, jika term hadis di atas dikaitkan dengan makna lain bagi term al fuqara' seperti yang dinyatakan di dalam QS al Fatir/35: 15 maka term al fuqara' dapat dipahami sebagai orang yang menggantungkan hidupnya kepada Allah. Dan jika term al nisa' juga dipahami dengan makna yang lain, seperti dinyatakan dalam QS Ali ' $I m r a n / 3: 14$, maka term al nisa' dapat dipahami sebagai orang yang menggantungkan hidupnya pada syahwat seksualnya. ${ }^{37}$

\footnotetext{
${ }^{33}$ Kementrian Agama RI., Mushaf al-Qur'an dan Terjemah, h. 7.

${ }^{34} \mathrm{Ibid}$, h. 28.

${ }^{35}$ Al-Bukhari, al-Jami' al-Sahih, Juz 4, h. 117.

${ }^{36}$ Arifuddin Ahmad, op.cit, h. 87.

${ }^{37}$ Ibid, h. 87-88.
} 
Dengan demikian, jika memperhatikan keserasian makna di dalam hadis, maka dapat dipahami bahwa yang dimaksudkan adalah umumnya calon penghuni surga adalah al fuqara' dalam pengertian mereka yang menggantungkan hidupnya kepada Allah swt. dan umumnya calon penghuni neraka adalah al nisa' dalam pengertian mereka yang menggantungkan hidupnya pada syahwat seksualnya. ${ }^{38}$

Selain tekhnik interpretasi teksual, interpretasi kontekstual dan interpretasi intertekstual, Ali Mustafa Yaqub menambahkan metode memahami hadis Nabi salah satu metodenya tidak terlepas dari metode al Tafsir al Maudhu' $i$ (Tafsir Tematik) pada ilmu tafsir dalam memahami ayat ayat al-Qur'an. Dalam memahami hadis, perlu menyeleksi terlebih dahulu hadis hadis sahih dan da'if lalu menggunakan langkah langkah sebagai berikut:

1. Mengumpulkan semua riwayat dalam tema yang sama.

2. Mengkritisi riwayat riwayat tersebut, dengan menyeleksi yang mana sahih dan da'if.

3. Mengambil riwayat yang sahih lalu meninggalkan yang tidak sahih, mengambil hadis yang ma'mul (berlaku) dan meninggalkan hadis yang tidak berlaku, misalnya hadis yang telah di nasakh.

4. Mengambbil teks hadis yang maknanya jelas, lalu menyeleksi dari teks teks yang petunjuk maknanya tidak jelas.

5. Menafsirkan teks teks hadis yang tidak jelas petunjuk maknanya dengan teks teks hadis yang jelas maknanya, berdasarkan kaidah "lafas yang jelas dapat menafsirkan afas yang tidak jelas. ${ }^{39}$

\section{Simpulan}

Berdasarkan uraian di atas maka dapat diperoleh kesimpulan sebagai berikut. Pertama, Metode pemahaman hadis adalah cara yang ditempuh seseorang untuk memahami atau menafsirkan hadis Nabi saw. Kedua, Interpretasi tekstual adalah metode pemahaman hadis nabi yang berdasarkan teks semata. Interpretasi kontekstual adalah metode memahami hadis berdasarkan latar belakang munculnya hadis (asbab al wurud) yang dikaitkan dengan masa kekinian. Sementara itu, interpretasi intertekstual atau antarteks adalah metode memahami hadis dengan sistematika matan hadis bersangkutan atau hadis lain yang semakna atau ayat ayat al-Qur'an yang terkait.

\footnotetext{
${ }^{38}$ Arifuddin Ahmad, Metodologi Pemahaman Hadis; Kajian Ilmu Ma'ani al-Hadis, h. 88.

${ }^{39}$ Ali Mustafa Yaqub, Cara Benar Memahami Hadis, h. 135-136.
} 
Ekspose Volume 16, Nomor 1, Januari - Juni 2017

P-ISSN: 1412-2715, E-ISSN: 2616-4412

\section{Daftar Pustaka}

Al Qur'an al Karim

Ahmad, Arifuddin. Metodologi Pemahaman Hadis; Kajian Ilmu Ma'ani al Hadis. Makassar: Alauddin University Press, 2012.

Al-Bukhari, Muhammad bin Isma'il Abu 'Abdillah. al Jami' al Sahih. Juz 4. Cet. I; t.tt: Dar Tuq al Najjah, $1422 \mathrm{H}$.

Al-Naisaburi, Muslim bin al Hajjaj Abu al Hasan al Qusyiri. Sahih Muslim. Juz 2 .Beirut: Dar Ihya' al Turas al 'Arabi, t.th.

Al-Salih, Subhi. 'Ulum al Hadis wa Mustalah. Beirut: Dar al Ilm al Malayin, 1977.

Al-Zuhaili, Wahbah. Al Qur'an al Karim wa Bunyatuhu al Tasyri'iyyah wa khasa 'isuhu al Khadariyyah. Beirut: Dar al Fikr, 1993.

Asse, Ambo. Studi Hadis Maudhu'i (Suatu Kajian Metodologi Holistik). Cet. I; Makassar: Alauddin University Press, 2013.

Departemen Pendidikan Nasional. Kamus Bahasa Indonesia. Jakarta: Pusat Bahasa, 2008.

Ismail, M. Syuhudi. Hadis Nabi yang Tekstual dan Kontekstual; Telaah Ma'ani al Hadits tentang Ajaran Islam yang Universal, Temporal dan Lokal. Cet. I; Jakarta: Bulan Bintang, 1994.

Kementrian Agama RI. Mushaf al Qur'an dan Terjemah. Bandung: Insan Kamil, 2009.

Mustafa Yaqub, Ali, Cara Benar Memahami Hadis, Pejaten Barat Jakarta: Pustaka Firdaus, 2016.

Qardawi, Yusuf. Kaifa Nata'amal ma'a al Sunnah al Nabawiyyah: Ma'alim wa Dawabit. terj. Saifullah Kamalie. Metode Memahami as Sunnah dengan Benar. Jakarta: Media Da'wah, 1994. 